\title{
Implementasi Bahan Ajar Persamaan Diferensial dengan Metode Guided Discovery Berbantuan Software Mathematica untuk Meningkatkan Pemahaman Konsep
}

\author{
Desty Haswati ${ }^{1}$, Dian Nopitasari ${ }^{2 *}$ \\ ${ }^{1,2}$ Universitas Muhammadiyah Tangerang, Kota Tangerang, Provinsi Banten 15118, Indonesia \\ Pengiriman: 28 Juli 2019; Diterima: 23 Oktober 2019; Publikasi: 30 Oktober 2019 \\ DOI: https://doi.org/10.31629/jg.v4i2.1358
}

\begin{abstract}
Abstrak
Penelitian ini bertujuan untuk mengkaji peningkatan kemampuan pemahaman konsep matematis mahasiswa menggunakan bahan ajar persamaan diferensial dengan metode Guided Discovery berbantuan software Mathematica. Penelitian ini adalah penelitian kuasi eksperimen dengan pretes postes Control Group Design. Subjek penelitian adalah mahasiswa semester VI Prodi Pendidikan Matematika Universitas Muhammadiyah Tangerang dengan sampel dua kelas yang dipilih berdasarkan teknik simple random sampling. Kelas eksperimen menggunakan bahan ajar persamaan diferensial dengan metode Guided Discovery berbantuan software Mathematica sedangkan kelas kontrol menggunakan bahan ajar biasa. Hasil penelitian menunjukkan bahwa peningkatan kemampuan pemahaman konsep matematis mahasiswa pada kelas eksperimen lebih tinggi daripada kemampuan pemahaman konsep matematis mahasiswa kelas kontrol. Rata-rata gain ternormalisasi mahasiswa kelas eksperimen berada pada kategori sedang dan tinggi. Sedangkan rata-rata gain ternormalisasi mahasiswa kelas kontrol pada kategori rendah dan sedang.
\end{abstract}

Kata kunci: bahan ajar; persamaan diferensial; guided discovery; software mathematica; pemahaman konsep

\begin{abstract}
This study aims to examine the improvement of students' understanding of mathematical concepts using teaching materials in differential equations course with the Guided Discovery method aided by Mathematica software. This research is a quasi-experimental study with pretest posttest Control Group Design. The subjects of the study were the sixth semester students of Mathematics Education Study Program, Universitas Muhammadiyah Tangerang with a sample of two classes selected based on simple random sampling technique. The experimental class used teaching material in differential equations course with Guided Discovery method assisted by Mathematica software while the control class used ordinary teaching materials. The results showed that the increase in the ability to understand mathematical concepts of students in the experimental class was higher than the ability to understand mathematical concepts of control class students. The average normalized gain of experimental class students is in the medium and high categories. While the normalized gain of control class students is in the low and medium categories.
\end{abstract}

Keywords: teaching material; differential equation; guided discovery; Mathematica software; mathematical concepts understanding 


\section{JURNAL GANTANG. Oktober 2019; IV(2): 97-102 \\ p-ISSN. 2503-0671 \\ e-ISSN. 2548-5547}

\section{Pendahuluan}

Persamaan diferensial adalah persamaan matematika untuk fungsi satu variabel atau lebih, yang menghubungkan nilai fungsi itu sendiri dan turunannya dalam berbagai orde (Santosa, Musthofa, \& Malahayati, 2013). Persamaan diferensial adalah salah satu mata kuliah wajib bagi mahasiswa pendidikan matematika, mata kuliah ini berada pada semester enam Program Studi Pendidikan Matematika Universitas Muhammadiyah Tangerang. Mata kuliah persamaan diferensial dapat diikuti oleh mahasiswa jika telah mempelajari mata kuliah prasyarat, yaitu kalkulus diferensial dan kalkulus integral. Untuk itu, persamaan diferensial harus dikuasai oleh setiap calon guru matematika, namun demikian yang peneliti temukan di lapangan bahwa kemampuan mahasiswa dalam memahami persamaan diferensial masih relatif rendah.

Berdasarkan hasil observasi selama peneliti mengajarkan mata kuliah persamaan diferensial, rendahnya pemahaman konsep mahasiswa bukan karena mahasiswa tidak mampu menyelesaikan soal-soal yang diberikan oleh dosen, tetapi lebih disebabkan karena kurangnya pemahaman konsep yang mendasar pada terutama pada konsep integral dan turunan. Sebagai contoh, masih banyak mahasiswa yang belum memahami konsep turunan dan integral yang merupakan prasyarat untuk mata kuliah persamaan diferensial. Fakta di lapangan membuktikan bahwa dengan hanya menggunakan model dan strategi mengajar saja tidak cukup, tetapi harus dibantu dengan bahan ajar yang disusun oleh dosen yang bersangkutan yang disesuaikan dengan kurikulum yang ada.

Ada beberapa variabel penentu hasil belajar mengajar yang berupa input, motivasi belajar, dosen, kurikulum, proses belajar mengajar, sistem penilaian, media pembelajaran, dan bahan ajar. Sejalan dengan proses belajar mengajar, kegiatan belajar mengajar mengandung sejumlah komponen yang meliputi tujuan, bahan ajar atau pelajaran, kegiatan belajar mengajar, metode mengajar, alat bantu dan sumber evaluasi (Sutikno \& Fathurrohman, 2010).

Sementara itu, salah satu kelemahan penerapan model pembelajaran selama ini di kelas adalah keterbatasan sarana dan fasilitas untuk mendukung visualisasi masalah yang dibahas dan melakukan penilaian terhadap pemecahan masalah yang sudah dibuat, dan hal ini dapat ditanggulangi dengan menerapkan pembelajaran berbasis teknologi informasi dan komunikasi (Warmada, 2003). Peran TIK ini dapat memberikan kesempatan kepada mahasiswa untuk mengeksplorasi sendiri konsep yang dipelajari, khususnya konsep turunan dan integral. Oleh karena itu penggunaan media khususnya TIK akan berdampak pada pembelajaran yang lebih berorientasi pada mahasiswa (Sanjaya, 2010), karena dapat membantu mahasiswa memvisualisasikan konsep matematika yang abstrak dan juga mengecek hasil dari permasalahan yang sedang dikerjakan.

Software yang dapat digunakan pada bahan ajar adalah software Mathematica. Mathematica adalah suatu sistem aljabar komputer (CAS, Computer Algebra System) yang mengintegrasikan kemampuan komputasi (Simbolik, numerik), visualisasi (grafik), bahasa pemrograman, dan pengolahan kata (word processing) ke dalam suatu lingkungan yang mudah digunakan (Razali, 2008). Bahan ajar yang akan dibuat berupa modul dengan berbantuan software Mathematica.

Latar belakang ini kemudian melandasi peneliti untuk membuat bahan ajar berupa modul pembelajaran persamaan diferensial dengan metode guided discovery berbantuan software mathematica agar dapat mengembangkan kemampuan pemahaman konsep persamaan diferensial. Menurut Bruner, penemuan terbimbing (Guided Discovery) adalah metode pengajaran yang berbasis inquiri, sebuah teori pembelajaran konstruktif yang terdapat pada situasi problem solving dimana mahasiswa menggunakan pengalaman dan pengetahuan mereka untuk menemukan fakta, hubungan, dan kebenaran-kebenaran baru untuk dipelajari 
(Winataputra, 2007). Sehingga dari pendapat tersebut, dapat disimpulkan bahwa metode guided discovery merupakan suatu metode pembelajaran yang dapat mengarahkan mahasiswa untuk dapat membangun pengetahuannya sendiri melalui penemuan suatu konsep dan pengetahuan baru dibawah bimbingan dosen. Inti metode pembelajaran guided discovery ini yaitu mengubah kondisi belajar yang semula pasif menjadi aktif dan kreatif.

Mahasiswa pendidikan matematika sebagai calon guru diharapkan dapat memiliki pemahaman yang lebih mendalam, karena pemahaman konsep matematis yang dimiliki nantinya akan ditransfer kepada siswanya. Karena apabila seorang calon guru yang memiliki pemahaman mendalam mengenai suatu topik dalam pembelajaran matematika, maka mahasiswa tersebut juga akan lebih mudah memberikan pemahaman kepada siswanya.

Definisi pemahaman konsep menurut Kilpatrick adalah kemampuan siswa untuk memahami konsep, operasi dan relasi yang ada dalam matemtaika (Findell, 2002). Orang yang memiliki pemahaman konsep akan mampu mengkonstruksi makna yang diperoleh selama proses pembelajaran berlangsung baik melalui komunikasi secara lisan dan tulisan.

Berdasarkan latar belakang masalah di atas, maka tujuan penelitian ini adalah untuk mengetahui apakah bahan ajar persamaan diferensial dengan metode guided discovery berbantuan software mathematica dapat meningkatkan pemahaman konsep mahasiswa. Indikator pemahaman konsep yang diukur dalam penelitian ini adalah sebagai berikut: 1) Menyatakan ulang sebuah konsep, 2) Menyajikan konsep dalam berbagai bentuk representasi, 3) Memberikan contoh dan non contoh, dan 4) Menggunakan konsep untuk meyelesaikan masalah matematis (Shadiq, 2009).

\section{Metode Penelitian}

Penelitian ini adalah penelitian kuasi eksperimen. Kuasi eksperimen merupakan jenis eksperimen yang belum memenuhi persyaratan seperti cara eksperimen yang dapat dikatakan ilmiah yang mengikuti peraturan-peraturan tertentu (Arikunto, 2011). Teknik pengambilan sampel menggunakan teknik simple random sampling. Pada penelitian ini kelompok eksperimen menggunakan bahan ajar persamaan diferensial dengan metode guided discovery berbantuan software mathematica, sedangkan kelompok kontrol menggunakan bahan ajar biasa.

Populasi pada penelitian ini adalah mahasiswa semester VI Prodi Pendidikan Matematika Universitas Muhammadiyah Tangerang dengan sampel kelas A2 sebagai kelas eksperimen dan A1 sebagai kelas kontrol. Teknik sampling penelitian ini adalah simple random sampling. Instrumen penelitian yang digunakan dalam penelitian ini adalah tes kemampuan pemahaman konsep matematis yang terdiri dari 4 butir soal uraian dengan 4 indikator yaitu, 1) Menyatakan ulang sebuah konsep, 2) Menyajikan konsep dalam berbagai bentuk representasi, 3) Memberikan contoh dan non contoh, dan 4) Menggunakan konsep untuk meyelesaikan masalah matematis. Setiap butir soal mewakili masing-masing.

\section{Hasil dan Pembahasan}

Hasil analisis pretes diperoleh bahwa kelas yang dijadikan sampel penelitian berasal dari populasi yang tidak berdistribusi normal. Berikut hasil uji normalitas dari pretes.

Tabel 1

Hasil uji normalitas pretes

\begin{tabular}{llrrr}
\hline & Kelas & \multicolumn{3}{c}{ Kolmogorov-Smirnov ${ }^{\mathrm{a}}$} \\
& & Statistic & df & Sig. \\
\hline \multirow{2}{*}{ Pretes } & Eksperimen & 0,202 & 24 & 0,013 \\
\cline { 2 - 5 } & Kontrol & 0,266 & 25 & 0,000 \\
\hline
\end{tabular}

Tabel 1 menunjukkan bahwa nilai signifikansi (sig.) kelas eksperimen sebesar 0,013 sedangkan kelas kontrol sebesar 0,000. Berdasarkan kriteria pengujian, nilai sig. Kelas eksperimen dan kelas kontrol $<0,05$ maka $\mathrm{H}_{0}$ ditolak. Artinya kelas eksperimen dan kelas kontrol berasal dari populasi yang tidak berdistribusi normal. Untuk melihat kemampuan 


\section{JURNAL GANTANG. Oktober 2019; IV(2): 97-102 \\ p-ISSN. 2503-0671 \\ e-ISSN. 2548-5547}

pemahaman konsep pada kedua kelas dilakukan uji non parametrik dengan menggunakan uji Mann Whitney.

Perbedaan rata-rata skor pretes kelas eksperimen dan kelas kontrol adalah 2,10. Berdasarkan hasil pretes pada kedua kelas tersebut maka kelas A2 dipilih sebagai kelas eksperimen dan kelas A1 dipilih sebagai kelas kontrol. Berikut hasil statistik deskriptif pretes dan hasil uji Mann Whitney.

Tabel 2

Statistik deskriptif dan hasil uji Mann Whitney pretes

\begin{tabular}{lllll}
\hline Kelas & N & $\begin{array}{l}\text { Rata- } \\
\text { rata }\end{array}$ & $\begin{array}{l}\text { Std. } \\
\text { Dev }\end{array}$ & $\begin{array}{l}\text { Sig. } \\
\text { (2-tailed) }\end{array}$ \\
\cline { 1 - 4 } Eksperimen & 24 & 68,46 & 5,12 & \multirow{2}{*}{0,754} \\
\cline { 1 - 4 } Kontrol & 25 & 70,56 & 4,87 & \\
\hline
\end{tabular}

Berdasarkan Tabel 2 di atas nilai sig. (2tailed) yaitu 0,754 dimana nilai signifikansi tersebut lebih besar dari 0,05 maka $\mathrm{H}_{0}$ diterima. Artinya bahwa kedua sampel memiliki kondisi yang sama yaitu memiliki kemampuan pemahaman konsep matematis yang sama.

Pada kelas eksperimen diterapkan pembelajaran menggunakan bahan ajar persamaan diferensial dengan metode guided discovery berbantuan software mathematica. Sedangkan pada kelas kontrol diterapkan pembelajaran dengan menggunakan bahan ajar biasa. Setelah diberi perlakuan, diperoleh data kemampuan pemahaman konsep matematis pada kedua kelas. Hasil analisis statistik deskriptif postes disajikan dalam tabel berikut.

Tabel 3.

Statistik deskriptif postes

\begin{tabular}{lccccc}
\hline Kelas & N & $\begin{array}{l}\text { Rata- } \\
\text { rata }\end{array}$ & $\begin{array}{l}\text { Std. } \\
\text { Dev }\end{array}$ & Min & Maks \\
\hline Eksperimen & 24 & 79,54 & 7,91 & 70 & 95 \\
\hline Kontrol & 25 & 68,12 & 8,45 & 60 & 90 \\
\hline
\end{tabular}

Tabel 3 menyatakan bahwa selisih ratarata kelas eksperimen dan kelas kontrol sebesar 11,42 . Untuk mengetahui apakah rata-rata postes kelas eksperimen dan kelas kontrol berbeda atau tidak maka dilakukan uji statistik. Sebelum dilakukan uji analisis data postes terlebih dahulu dilakukan uji prasyarat yaitu uji normalitas. Berikut disajikan hasil uji normalitas postes kedua kelas.

Tabel 4.

Hasil uji normalitas postes

\begin{tabular}{llccc}
\hline \multirow{2}{*}{ Kelas } & \multicolumn{3}{c}{ Kolmogorov-Smirnov } \\
& & Statistic & df & Sig. \\
\hline \multirow{2}{*}{ Pretes } & Eksperimen & 0,185 & 24 & 0,033 \\
\cline { 2 - 5 } & Kontrol & 0,252 & 25 & 0,000 \\
\hline
\end{tabular}

Hasil yang diperoleh dari uji normalitas postes berdasarkan Tabel 4 adalah nilai sig. Kelas eksperimen yaitu 0,033 dan sig. kelas kontrol yaitu 0,000 , karena nilai sig. Kedua kelas tersebut maka $\mathrm{H}_{0}$ ditolak. Artinya baik kelas eksperimen maupun kelas kontrol tidak berdistribusi normal. Dikarenakan sampel tidak berdistribusi normal, maka dilakukan uji non parametrik. Hasil uji Mann Whitney disajikan tabel 5 berikut ini.

Tabel 5.

Hasil uji Mann Whitney postes

\begin{tabular}{lcc}
\hline Kelas & $\begin{array}{c}\text { Asymp Sig. } \\
\text { (2-tailed) }\end{array}$ & Ket. \\
\hline Eksperimen & 0,000 & $\mathrm{H}_{0}$ ditolak \\
\hline Kontrol & & \\
\hline
\end{tabular}

Hasil uji Mann Whitney pada Tabel 5 diperoleh nilai sig. 0,000. Karena nilai sig. lebih kecil dari 0,05 maka $\mathrm{H}_{\mathrm{o}}$ ditolak artinya rata-rata kemampuan pemahaman konsep mahasiswa kelas eksperimen lebih baik daripada kelas kontrol. Untuk melihat ada atau tidaknya peningkatan dari setiap indikator kemampuan pemahaman konsep matematis mahasiswa dilakukan analisis rata-rata skor pada setiap butir soal. Adapun rincian indikator kemampuan pemahaman konsep beserta nomor soal instrumen yang telah digunakan dapat dilihat pada tabel 6 berikut.

Tabel 6.

Indikator kemampuan pemahaman konsep dan nomor soal

\begin{tabular}{cc}
\hline Indikator & $\begin{array}{c}\text { Nomor } \\
\text { Soal }\end{array}$ \\
\hline Menyatakan ulang sebuah konsep & 1 \\
\hline
\end{tabular}




\begin{tabular}{ll}
\hline $\begin{array}{l}\text { Menyajikan konsep dalam berbagai } \\
\text { bentuk representasi }\end{array}$ & 2 \\
\hline Memberikan contoh serta non contoh & 3 \\
\hline $\begin{array}{l}\text { Menggunakan konsep untuk } \\
\text { meyelesaikan masalah matematis }\end{array}$ & 4 \\
\hline
\end{tabular}

Untuk melihat peningkatan masingmasing indikator kemampuan pemahaman konsep mahasiswa yang pembelajarannya menggunakan bahan ajar dengan metode guided discovery berbantuan software mathematica, maka dilakukan pengolahan data untuk menentukan berapa besar peningkatannya yaitu menggunakan data gain ternormalisasi dan diperoleh hasil sebagai berikut.

Tabel 7.

Hasil $N$-gain per butir soal

\begin{tabular}{cccccc}
\hline $\begin{array}{c}\text { No. } \\
\text { soal }\end{array}$ & $\begin{array}{c}\text { Rata-rata } \\
\text { N.gain } \\
\text { Kelas Eks }\end{array}$ & $\begin{array}{c}\text { Katego } \\
\text { ri }\end{array}$ & $\begin{array}{c}\text { No. } \\
\text { soal }\end{array}$ & $\begin{array}{c}\text { Rata-rata } \\
\text { N-gain } \\
\text { Kelas Kntrl }\end{array}$ & $\begin{array}{c}\text { Katego } \\
\text { ri }\end{array}$ \\
\hline 1 & 0,43 & Sedang & 1 & 0,34 & Sedang \\
\hline 2 & 0,58 & Sedang & 2 & 0,13 & Rendah \\
\hline 3 & 0,30 & Sedang & 3 & 0,22 & Rendah \\
\hline 4 & 0,74 & Tinggi & 4 & 0,37 & Sedang \\
\hline
\end{tabular}

Berdasarkan Tabel 7 tersebut terlihat bahwa rata-rata $\mathrm{N}$-gain pada kelas eksperimen tertinggi adalah 0,74 dengan indikator menggunakan konsep untuk meyelesaikan masalah matematis. Pada kelas kontrol, nilai $N$ gain terendah yaitu 0,13 dengan indikator menyajikan konsep dalam berbagai bentuk representasi. Pada kelas eksperimen nilai $N$-gain hanya pada kategori sedang dan tinggi, sedangkan pada kelas kontrol, nilai $\mathrm{N}$-gain berada pada kategori rendah dan sedang.

Pembelajaran dengan pemberian bahan ajar persamaan diferensial dengan metode guided discovery berbantuan mathematica mengalami peningkatan kemampuan pemahaman konsep mahasiswa terutama untuk indikator menggunakan konsep untuk menyelesaikan masalah matematis, sedangkan ketiga indikator lainnya, yaitu indikator menyatakan ulang sebuah konsep, menyajikan konsep dalam berbagai representasi serta memberikan contoh dan non contoh mengalami peningkatan pada ketegori sedang. Sama halnya dengan kelas eksperimen, pembelajaran persamaan diferensial dengan menggunakan bahan ajar biasa pada kelas kontrol juga mengalami peningkatan. Pada indikator menyatakan ulang sebuah konsep menggunakan konsep untuk meyelesaikan masalah matematis peningkatannya termasuk kategori sedang. Sedangkan dua indikator lainnya, yaitu indikator menyajikan konsep dalam berbagai representasi serta memberikan contoh dan non contoh tergolong peningkatan kategori rendah. Peningkatan setiap indikator kemampuan pemahaman konsep matematis menggunakan bahan ajar dengan metode guided discovery berbantuan mathematica pada mata kuliah persamaan diferensial lebih tinggi daripada peningkatan kemampuan pemahaman konsep mahasiswa menggunakan bahan ajar biasa.

Penyebab adanyanya perbedaan peningkatan kemampuan pemahaman konsep matematis mahasiswa yang menggunakan bahan ajar persamaan diferensial dengan metode guided discovery berbantuan mathematica dengan mahasiswa yang menggunakan bahan ajar biasa adalah karena pada bahan ajar persamaan diferensial berbantuan software mathematica mahasiswa dapat menyelesaikan persamaan diferensial bukan hanya berdasarkan algoritma tetapi juga dengan bantuan software. Bahan ajar persamaan diferensial berbasis software mathematica membuat mahasiswa dapat menyelesaikan masalah sesuai dengan kreativitas masing-masing serta mampu mengembangkan pola pikir mahasiswa baik menggunakan perhitungan secara algoritmik maupun secara komputasi sehingga dapat meningkatkan kemampuan pemahaman konsep matematis mahasiswa. Hal ini sejalan dengan penelitian yang telah dilakukan oleh Novitasari yang menyatakan bahwa pembelajaran berbasis TIK dapat berpengaruh terhadap pemahaman konsep matematis (Novitasari, 2016).

\section{Kesimpulan}

Berdasarkan paparan hasil penelitian 
JURNAL GANTANG. Oktober 2019; IV(2): 97-102

p-ISSN. 2503-0671

e-ISSN. 2548-5547

yang telah dilaksanakan, dapat disimpulkan bahwa kemampuan pemahaman konsep matematis mahasiswa yang menggunakan bahan ajar persamaan diferensial dengan metode guided discovery berbantuan software mathematica lebih baik daripada mahasiswa yang menggunakan bahan ajar biasa dalam pembelajaran persamaan diferensial. Indikator kemampuan pemahaman konsep matematis memiliki peningkatan tertinggi pada indikator menggunakan konsep untuk meyelesaikan masalah matematis yaitu dengan skor peningkatan ( $N$-gain) 0,74 dan termasuk dalam kategori tinggi. Penggunaan bahan ajar persamaan diferensial dengan metode guided discovery berbantuan software mathematica dapat digunakan sebagai salah satu alternatif untuk meningkatkan kemampuan pemahaman konsep matematis mahasiswa.

\section{Ucapan Terimakasih}

Artikel ini adalah hasil penelitian dengan skema Penelitian Dosen Pemula Tahun 2019 yang dibiayai menggunakan dana yang bersumber dari DRPM DIKTI. Oleh karena itu penulis mengucapkan terimakasih kepada DRPM DIKTI atas dukungan pendanaannya demi kesuksesan penelitian ini.

\section{Referensi}

Arikunto, S. (2011). Dasar-dasar evaluasi pendidikan. Jakarta: Buku Aksara.

Findell, B. (2002). Adding it up: Helping children learn mathematics. In Book Reviews.

Novitasari, D. (2016). Pengaruh penggunaan multimedia interaktif terhadap kemampuan pemahaman konsep matematis siswa. FIBONACCI: Jurnal Pendidikan Matematika Dan Matematika. https://doi.org/10.24853/fbc.2.2.8-18

Razali, M. (2008). Cara mudah menyelesaikan matematika dengan mathematica. Yogyakarta: Andi Publisher.

Sanjaya, W. (2010). Strategi pembelajaran berorientasi standar proses pendidikan. System.

Santosa, S., Musthofa, M. W., \& Malahayati, M.
(2013). Penyelesaian masalah nilai batas persamaan diferensial Mathieu-Hill. Jurnal Fourier.

https://doi.org/10.14421/fourier.2013.22.91 $-103$

Shadiq, F. (2009). Strategi pembelajaran matematika. Bahan Ajar Diklat.

Sutikno, M. S., \& Fathurrohman, P. (2010). Strategi belajar mengajar melalui penanaman konsep umum \& konsep islami. In Bandung: Refika Aditama.

Warmada, I. W. (2003). Problem Based Learning (PBL) berbasis Teknologi Informasi (ICT). Jurnal Teknik Geologi FT UGM, 5. Retrieved from http://warmada.staff.ugm.ac.id/Articles/pbl -ict150504.pdf

Winataputra, U. S. (2007). Teori belajar dan pembelajaran. Jakarta: Universitas Terbuka. 